\title{
Dynamics and protein-solvent interactions of hemoglobin in T and R quaternary conformation
}

\author{
Chiara Caronna and Antonio Cupane * \\ Istituto Nazionale per la Fisica della Materia (INFM) and Dipartimento di Scienze Fisiche ed \\ Astronomiche (DSFA), University of Palermo, via Archirafi, 36, I-90123 Palermo, Italy
}

\begin{abstract}
In this work we report the thermal behaviour of the amide $\mathrm{I}^{\prime}$ band of carbonmonoxy and deoxy hemoglobin in $65 \%$ $\mathrm{v} / \mathrm{v}$ glycerolD $\mathrm{D}_{8} / \mathrm{D}_{2} \mathrm{O}$ solutions and in the temperature interval 10-295 K. Following recent suggestions in the literature, we analyze the amide $\mathrm{I}^{\prime}$ band in terms of two components, one at about $1630 \mathrm{~cm}^{-1}$ and the other at about $1650 \mathrm{~cm}^{-1}$, that are assigned to solvent-exposed and buried $\alpha$-helical regions, respectively.

For deoxy hemoglobin (in T quaternary structure) both components are narrower with respect to carbonmonoxy hemoglobin (in R quaternary structure), while the peak frequency blue shift observed, upon increasing temperature, for the component at about $1630 \mathrm{~cm}^{-1}$ is smaller. The reported data provide evidence of the dependence of hemoglobin dynamic properties upon the protein quaternary structure and suggest a more compact $\alpha$-helical structure of hemoglobin in $\mathrm{T}$ conformation, with reduced population of low-frequency modes involving the solvent and protein.
\end{abstract}

\section{Introduction}

It is well known that hemoglobin can adopt two (at least two) well-defined different quaternary conformations: the $\mathrm{T}$ (tense) conformation, characterized by stronger subunit interactions and low ligand affinity, and the $\mathrm{R}$ (relaxed) conformation, characterized by weaker subunit interactions and high ligand affinity [20]. The ligand-linked switching between the $\mathrm{T}$ and R quaternary structures is the key mechanism for the cooperative ligand binding to hemoglobin. The origin of the different functional properties of the $\mathrm{R}$ and $\mathrm{T}$ conformations has been investigated in the fundamental works of Perutz and collaborators $[21,22]$ and has been traced to the different stereochemical properties of the two quaternary conformations. The role of protein-solvent interactions in the $\mathrm{T} \leftrightarrow \mathrm{R}$ quaternary equilibrium has also been evidenced through studies of cosolvents effects on the oxygen affinity [2,4].

In recent years, however, a more complete picture has emerged, in which proteins are considered as dynamic entities whose complex energy landscape is characterized by the presence of a large number of nearly degenerate minima which have been called "conformational substates" (CS) [9]. At room temperature proteins fluctuate among the thermally accessible CS and these equilibrium fluctuations play a relevant role in determining the functional properties [18]. Studies of the dynamic properties of proteins and of the interplay between structure, dynamics and function are therefore an all-essential step toward the understanding of protein functionality. Myoglobin has up to now served as a paradigm for such kind of studies; in fact, the equilibrium fluctuations and the conformational relaxations of this protein have

\footnotetext{
*Corresponding author: Dr. Antonio Cupane, Dipartimento di Scienze Fisiche ed Astronomiche, Università di Palermo, via Archirafi 36, I-90123, Palermo, Italy. Tel.: +39 091 6234221; Fax: +39 091 6162461; E-mail: cupane@ fisica.unipa.it.
} 
been studied using a variety of experimental techniques including flash photolysis [24], optical absorption [5] and FTIR spectroscopy [13], elastic and quasi-elastic neutron scattering [8], X-ray diffraction [10] and Mössbauer spectroscopy [19].

Much less is known about the CS of hemoglobin, although infrared spectra at room temperature have shown the existence of multiple $\mathrm{CO}$ stretch bands also for this molecule [23], and the dynamics of hemoglobin encapsulated in porous silica hydrogels have been studied through flash photolysis [15]. In particular, the characterization of the equilibrium fluctuations of hemoglobin and of their dependence upon the protein quaternary structure is lacking.

In this work we address the above problems by investigating through FTIR spectroscopy the thermal behaviour of the amide $\mathrm{I}^{\prime}$ bands of deoxy $(\mathrm{Hb})$ and carbonmonoxy $(\mathrm{HbCO})$ hemoglobin in glycerolD $8 / \mathrm{D}_{2} \mathrm{O}$ solutions and in the temperature range 10-295 K. Indeed, it is well known that IR bands of H-bonded groups are temperature dependent, since temperature affects H-bonding [12]. For proteins, in particular, the amide $\mathrm{I}^{\prime}$ band tends to shift to higher frequency (while the amide $\mathrm{II}^{\prime}$ band tends to shift to lower frequency) with increasing temperature; this effect may be attributed to weakening of hydrogen bonds introduced by an increase of the average hydrogen bond angles due to thermal fluctuations [16]. Aim of our work is therefore to investigate the dynamic properties of hemoglobin in $\mathrm{T}$ and $\mathrm{R}$ quaternary conformations, at the level of the protein secondary structure. Moreover, the width of the amide $\mathrm{I}^{\prime}$ band is expected to give information on the existence and distribution of conformational substates of $\alpha$-helical regions of the protein.

\section{Materials and methods}

\subsection{Samples}

Hemoglobin was prepared from the blood of a single healthy individual as already described [3]. Stocks of about $16 \%$ by weight concentration were stored in liquid nitrogen under the oxy form. An appropriate amount was thawed immediately before the experiment; the protein was first concentrated to about $30 \%$ by weight and then diluted $1: 1$ with $\mathrm{D}_{2} \mathrm{O}$. This procedure was repeated ten times; after last step the sample was concentrated to about $30 \%$ by weight and then diluted $1: 2$ with glycerolD 8 . The final sample was a $65 \% \mathrm{v} / \mathrm{v}$ glycerol $\mathrm{D}_{8} / \mathrm{D}_{2} \mathrm{O}$ solution,containing $\sim 6.2 \mathrm{mM}$ (in heme) protein and 0.01 M phosphate buffer $\mathrm{pH} 7$.

To prepare $\mathrm{HbCO}$ and deoxy $\mathrm{Hb}$, the oxygenated hemoglobin solutions were first equilibrated with $\mathrm{CO}$ $\left(\mathrm{N}_{2}\right)$ by gently stirring under $\mathrm{CO}\left(\mathrm{N}_{2}\right)$ atmosphere for about $15 \mathrm{~min}$; a four-fold excess of sodium dithionite was added to both samples immediately before the experiments in order to ensure full reduction. The final $\mathrm{pD}$ of our samples was measured to be around 5.5. The high protein concentration used, together with the fact that the dimer-tetramer association constant in water-alcohol solutions is even larger than that measured in pure water [6], makes us confident that also $\mathrm{HbCO}$ in our samples is essentially in tetrameric form at all temperatures.

\subsection{FTIR spectra}

FTIR spectra were measured using a Jasco FTIR 140 spectrophotometer equipped with a PbS detector and an Oxford Microstat ${ }^{\mathrm{He}}$ dewar for measurements in the temperature range 300-10 K. The temperature was controlled with an Oxford ITC-503 temperature controller. Samples were placed in a cell mounting $\mathrm{CaF}_{2}$ windows and a $0.025 \mathrm{~mm}$ spacer. At each temperature the single beam spectrum in the 
$1000-4000 \mathrm{~cm}^{-1}$ wavenumber range was measured with 300 scans at $1 \mathrm{~cm}^{-1}$ resolution. The sample absorption spectra were calculated with respect to the empty cell. A cubic baseline was subtracted from each spectrum, using the Peakfit package. Deconvolutions of the amide I' bands in Gaussian components were performed by using a Marquardt type non linear least squares algorithm.

\section{Results and discussion}

IR spectra of the amide $\mathrm{I}^{\prime}$ band for $\mathrm{HbCO}$ and $\mathrm{Hb}$ in glycerol $\mathrm{D}_{8} / \mathrm{D}_{2} \mathrm{O}$ are shown as a function of temperature in Fig. 1. Visual inspection of spectra in Fig. 1 shows that, in analogy with recently reported data on parvalbumin [16], the amide $\mathrm{I}^{\prime}$ band shifts to the red upon lowering the temperature, while the shoulder on the red side grows. Moreover, it is also evident from Fig. 1 that the band relative to $\mathrm{Hb}$ is, at all temperatures, narrower than that relative to $\mathrm{HbCO}$.

Figure 2 shows the deconvolution of the amide $\mathrm{I}^{\prime}$ band of $\mathrm{Hb}$ at $10 \mathrm{~K}$ in terms of Gaussian components; fittings of analogous quality are obtained at all temperatures and also for HbCO. In Fig. 2 the Gaussian at
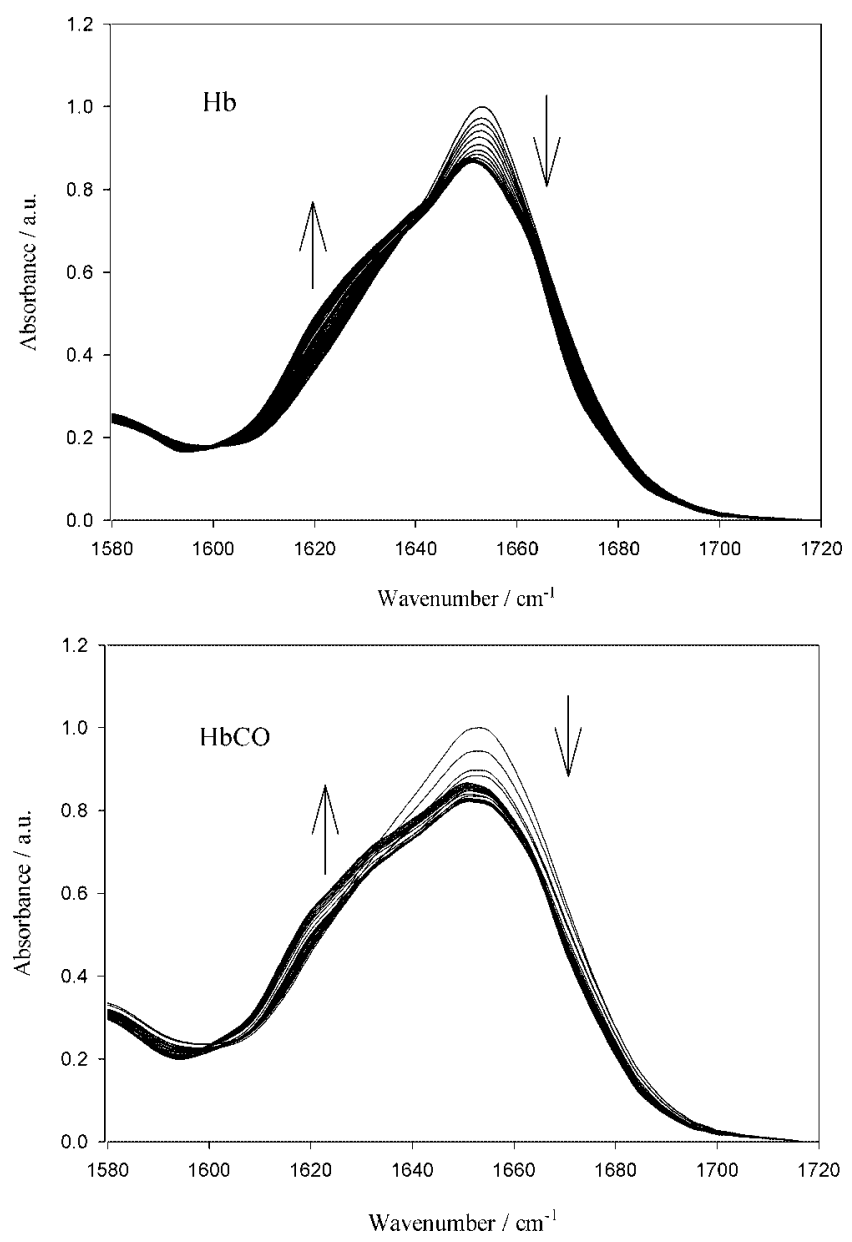

Fig. 1. IR absorption spectra (amide I' region) of $\mathrm{Hb}$ and $\mathrm{HbCO}$ in $65 \% \mathrm{v} / \mathrm{v}$ glycerolD $\mathrm{D}_{8} / \mathrm{D}_{2} \mathrm{O}$. The temperature was varied from 295 to $10 \mathrm{~K}$ in the direction of the arrows. 


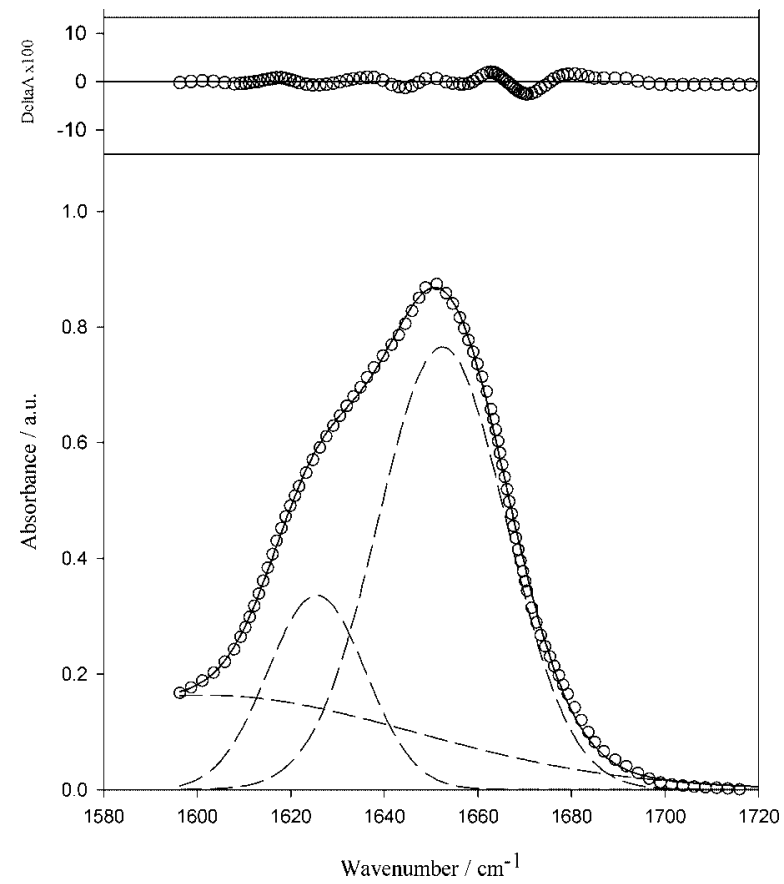

Fig. 2. Deconvolution of the amide $\mathrm{I}^{\prime}$ band of $\mathrm{Hb}$ at $10 \mathrm{~K}$ in terms of Gaussian components. Open circles are the experimental points, dashed lines the spectral components and the continuous line the overall calculated spectral profile. Residuals are shown in the upper panel on an expanded scale.

Table 1

Peak frequencies and widths of the two sub-bands of the amide $\mathrm{I}^{\prime}$ band at the highest and lowest temperatures for $\mathrm{Hb}$ and $\mathrm{HbCO}$

\begin{tabular}{|c|c|c|c|c|c|}
\hline & \multirow[t]{2}{*}{$T(\mathrm{~K})$} & \multicolumn{2}{|c|}{$1630 \mathrm{~cm}^{-1}$ component } & \multicolumn{2}{|c|}{$1650 \mathrm{~cm}^{-1}$ component } \\
\hline & & Peak frequency $\left(\mathrm{cm}^{-1}\right)$ & Width $\left(\mathrm{cm}^{-1}\right)$ & Peak frequency $\left(\mathrm{cm}^{-1}\right)$ & Width $\left(\mathrm{cm}^{-1}\right)$ \\
\hline $\mathrm{HbCO}$ & 10 & 1625.7 & 11.8 & 1654.2 & 15.0 \\
\hline & 295 & 1628.3 & 11.8 & 1655.0 & 15.3 \\
\hline $\mathrm{Hb}$ & 10 & 1625.5 & 10.5 & 1652.3 & 13.7 \\
\hline & 295 & 1627.4 & 10.5 & 1653.3 & 13.6 \\
\hline
\end{tabular}

$1600 \mathrm{~cm}^{-1}$ is needed as an extrapolation, while the other two Gaussian components take into account the amide $\mathrm{I}^{\prime}$ band. Our deconvolution is in agreement with the analysis by Meersman et al. [17] which show that, even after Fourier self-deconvolution, the amide $I^{\prime}$ band of metmyoglobin consists essentially of two sub-bands, while other sub-bands at $\sim 1620$ and $1668 \mathrm{~cm}^{-1}$ account for less than $10 \%$ of the spectrum. Following previous suggestions in literature [11,16], we attribute the component at around $1650 \mathrm{~cm}^{-1}$ to buried $\alpha$-helical regions of the protein, and the lower frequency component at $1630 \mathrm{~cm}^{-1}$ to groups that are most involved in direct hydrogen bonding with the solvent. Table 1 reports peak frequencies and widths of the two sub-bands at the highest and lowest temperatures for $\mathrm{Hb}$ and $\mathrm{HbCO}$.

The temperature dependence of spectral shifts is reported in Fig. 3. In agreement with data in the literature relative to parvalbumin [16], a blue shift is observed for both components upon increasing temperature. For the component at about $1650 \mathrm{~cm}^{-1}$ the overall blue shift is only $1 \mathrm{~cm}^{-1}$ and no difference is seen between $\mathrm{Hb}$ and $\mathrm{HbCO}$ while, for the component at about $1630 \mathrm{~cm}^{-1}$ the overall blue shift is $1.9 \mathrm{~cm}^{-1}$ for $\mathrm{Hb}$ and $2.6 \mathrm{~cm}^{-1}$ for $\mathrm{HbCO}$; moreover, a relevant difference between $\mathrm{Hb}$ and $\mathrm{HbCO}$ is 


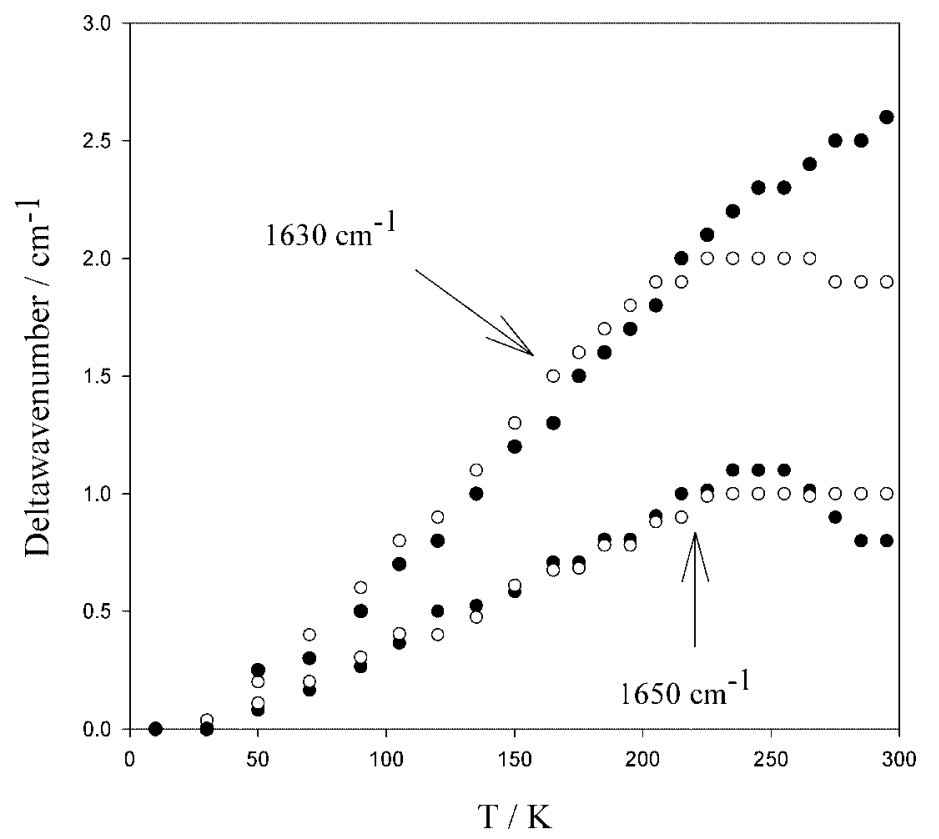

Fig. 3. Temperature dependence of the peak frequency shift (calculated with respect to $10 \mathrm{~K}$ ) for the two components. Closed symbols refer to $\mathrm{HbCO}$, open symbols to $\mathrm{Hb}$.

seen at temperatures higher than $225 \mathrm{~K}$. At difference with Manas et al. [16] and with Demmel et al. [7], we see no inflections at the solvent glass transition (160-180 K). Data in Table 1 show also that, as already noted from visual inspection of the spectra in Fig. 1, both components are narrower for $\mathrm{Hb}$ than for $\mathrm{HbCO}$.

The origin of the spectral red shifts observed upon lowering temperature for the amide $\mathrm{I}^{\prime}$ band has been discussed in recent works. It is attributed to the increase of average bond angles upon increasing the temperature, the increase being due to thermal fluctuations, whose effect is to weaken the hydrogen bonds [16]; in addition, volume expansion of the H-bond network has been suggested to contribute to spectral shifts [7]. These effects are larger for solvent exposed peptide groups where hydrogen bonds are made with a small molecule, such as water or $\mathrm{D}_{2} \mathrm{O}$.

A slightly different point of view considers anharmonic coupling of a high frequency vibrational mode (such as the $\mathrm{C}=\mathrm{O}$ stretch, in the case of amide $\mathrm{I}^{\prime}$ band) with low frequency mode(s) of the system $[1,14]$; these modes become populated as the temperature is increased, thereby causing a frequency shift of the vibrational mode.

In both cases, data reported in Fig. 3 indicate a different dynamic behaviour of the T quaternary conformation with respect to the $\mathrm{R}$ quaternary conformation, involving interaction of the protein with the solvent. One may suggest that, in the case of $\mathrm{Hb}$, stronger protein-solvent interactions lead to reduced thermal fluctuations and therefore to smaller spectral shifts. Analogously, one may also think that the population of the low frequency solvent librational mode(s) decreases at temperatures higher than $225 \mathrm{~K}$, and therefore a smaller red shift of the $\mathrm{C}=\mathrm{O}$ stretching mode is observed. In any case, the fact that the difference between $\mathrm{Hb}$ and $\mathrm{HbCO}$ is observed only at temperatures higher than $225 \mathrm{~K}$ suggests that the protein and solvent anharmonic motions that occur above the so called "dynamical transition" [8] are involved. 
Finally, the smaller values of the Gaussian widths reported in Table 1 indicate, for $\mathrm{Hb}$, a smaller amount of conformational heterogeneity at the level of secondary structure, both for buried and solvent exposed $\alpha$-helical regions; this is consistent with a more rigid and less heterogeneous structure of hemoglobin in $\mathrm{T}$ quaternary conformation, likely connected with the stronger protein-solvent interactions.

\section{Conclusion}

The data reported in this work provide evidence for different dynamic properties of the $\mathrm{T}$ and $\mathrm{R}$ quaternary conformations of hemoglobin. In particular, as compared to R-state hemoglobin, T-state hemoglobin appears to be characterized at room temperature by a more rigid and less heterogeneous secondary structure, with stronger hydrogen bonds between exposed $\alpha$-helical regions and solvent. Although more extensive experiments are necessary, one may speculate about the contribution of the above dynamic properties to the lowered ligand affinity of the T quaternary structure.

\section{Acknowledgements}

We are indebted to $\mathrm{Mr}$ G. Lapis of the cryogenic laboratory for technical help. This work has been supported by a COFIN 2000 grant from Italian MIUR.

\section{References}

[1] A. Bitler and S.S. Stavrov, Iron-histidine resonance Raman band of deoxyheme proteins: effects of anharmonic coupling and glass-liquid phase transition, Biophys. J. 77 (1999), 2764-2776.

[2] D. Bulone, A. Cupane and L. Cordone, Conformational and functional properties of haemoglobin in water-organic cosolvent mixtures: the effect of ethylene glycol and glycerol on the oxygen affinity, Biopolymers 22 (1983), 119-123.

[3] L. Cordone, A. Cupane, P.L. Sanbiagio and E. Vitrano, Effect of some monohydric alcohols on the oxygen affinity of hemoglobin: relevance of solvent dielectric constant and hydrophobicity, Biopolymers 18 (1979), 1975-1988.

[4] L. Cordone, A. Cupane, P.L. Sanbiagio and E. Vitrano, Effect of some organic cosolvent on the reaction of hemoglobin with oxygen, Biopolymers 20 (1981), 39-51.

[5] A. Cupane, M. Leone, E. Vitrano and L. Cordone, Structural and dynamical properties of heme pocket in myoglobin probed by optical spectroscopy, Biopolymers 27 (1988), 1977-1997.

[6] A. Cupane, E. Vitrano and L. Cordone, The effect of organic cosolvents on the dimer-tetramer equilibrium of human haemoglobin, J. Mol. Biol. 189 (1986), 343-351.

[7] F. Demmel, W. Doster, W. Petry and A. Schulte, Vibrational frequency shifts as a probe of hydrogen bonds: thermal expansion and glass transition of myoglobin in mixed solvents, Eur. Biophys. J. 26 (1997), 327-335.

[8] W. Doster, S. Cusack and W. Petry, Dynamical transition of myoglobin revealed by inelastic neutron scattering, Nature 337 (1989), 754-756.

[9] H. Frauenfelder, F. Parak and R.D. Young, Conformational substates in proteins, Annu. Rev. Biophys. Biophys. Chem. 17 (1988), 451-479.

[10] H. Frauenfelder, G.A. Petsko and D. Tsernoglu, Temperature dependent X-ray diffraction as a probe of protein structural dynamics, Nature 280 (1979), 558-563.

[11] R. Gimanshin, S. Williams, R.H. Callender, W.H. Woodruff and R.B. Dyer, Fast events in protein folding: relaxation dynamics of secondary and tertiary structure in native apomyoglobin, Proc. Natl. Acad. Sci. USA 94 (1997), 3709-3713.

[12] G.A. Jeffrey, An Introduction to Hydrogen Bonding, Oxford University Press, New York, 1997.

[13] J.B. Johnson, D.C. Lamb, H. Frauenfelder, J.D. Muller, B. McMahon, G.U. Nienhaus and R.D. Young, Ligand binding to heme proteins. VI. Interconversion of taxonomic substates in carbonmonoxymyoglobin, Biophys. J. 71 (1996), 15631573.

[14] A.D. Kaposi, J.M. Vanderkooi, W.W. Wright, J. Fidy and S.S. Stavrov, Influence of static and dynamic disorder on the visible and infrared absorption spectra of carbonmonoxy horseradish peroxidase, Biophys. J. 81 (2001), 3472-3482. 
[15] I. Khan, C.F. Shannon, D. Dantsker, A.J. Friedman, J. Perez Gonzalez de Apocada and J.M. Friedman, Sol-gel trapping of functional intermediates of hemoglobin: geminate and bimolecular recombination studies, Biochemistry 39 (2000), $16099-16109$.

[16] E.S. Manas, Z. Getahun, W.W. Wright, W.F. De Grado and J.M. Vanderkooi, Infrared spectra of amide groups in $\alpha$-helical proteins: evidence for hydrogen bonding between helices and water, J. Am. Chem. Soc. 122 (2000), 9883-9890.

[17] F. Meersmann, L. Smeller and K. Heremans, Comparative Fourier transform infrared spectroscopy study of cold-, pressure-, and heat-induced unfolding and aggregation of myoglobin, Biophys. J. 82 (2002), 2635-2644.

[18] G.U. Nienhaus and R.D. Young, Protein dynamics, in: Enciclopedia of Applied Biophysics, G.L. Trigg, ed., Vol. 15, VCH Publisher, New York, 1996, pp. 163-184.

[19] F. Parak, E.W. Knapp and D. Kucheida, Protein dynamics. Mossbauer spectroscopy on deoxymyoglobin crystals, J. Mol. Biol. 161 (1982), 177-194.

[20] M.F. Perutz, Stereochemistry of cooperative effects in haemoglobin, Nature 228 (1970), 726-739.

[21] M.F. Perutz, G. Fermi, B. Luisi, B. Shaanan and R.C. Liddington, Stereochemistry of cooperative mechanism in haemoglobin, Acc. Chem. Res. 20 (1987), 309-321.

[22] M.F. Perutz, A.J. Wilkinson, M. Paoli and G.G. Dodson, The stereochemical mechanism of the coperative effects in hemoglobin revisited, Annu. Rev. Biophys. Biomol. Struct. 27 (1998), 1-34.

[23] W.T. Potter, J.H. Hazzard, M.G. Choc, M.P. Tucker and W.S. Caughey, Infrared spectra of carbonyl hemoglobins: characterization of dynamic heme pocket conformers, Biochemistry 29 (1980), 6283-6295.

[24] P.J. Steinbach, A. Ansari, J. Berendzen, D. Braunstein, K. Chu, B.R. Cowen, P. Ehrenstein, H. Frauenfelder, J.B. Johnson, D.C. Lamb, S. Luck, J.R. Mourant, G.U. Nienhaus, P. Ormos, R. Philipp, A. Xie and R.D. Young, Ligand binding to heme proteins: connection between dynamics and function, Biochemistry 30 (1991), 3988-4001. 


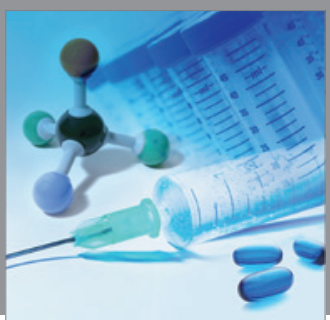

International Journal of

Medicinal Chemistry

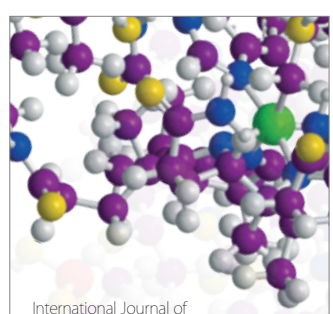

Carbohydrate Chemistry

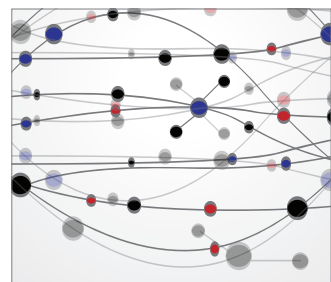

The Scientific World Journal
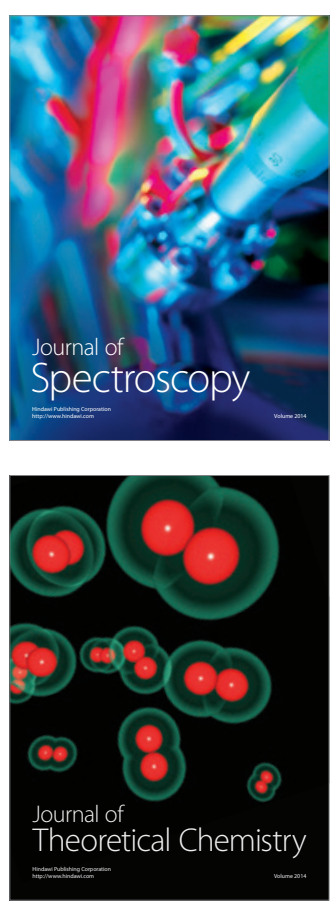
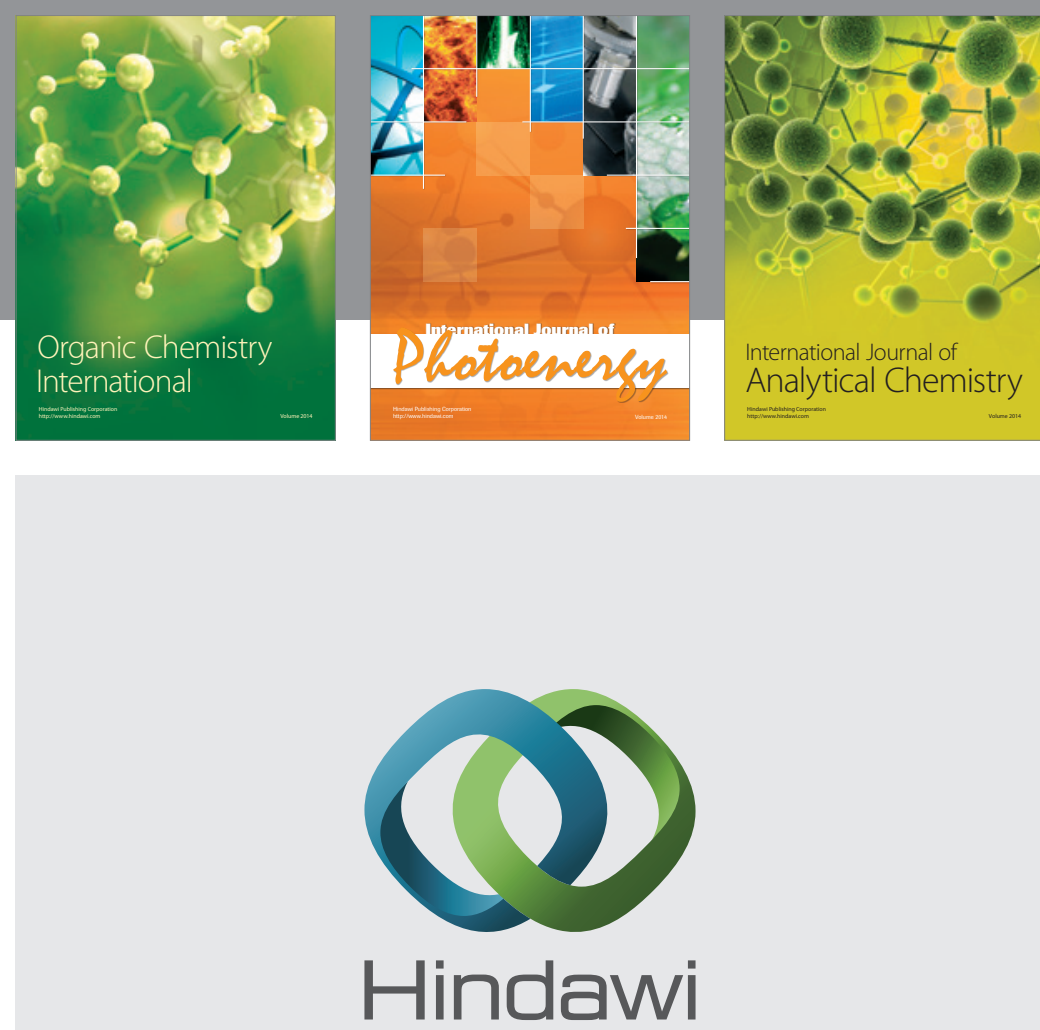

Submit your manuscripts at

http://www.hindawi.com
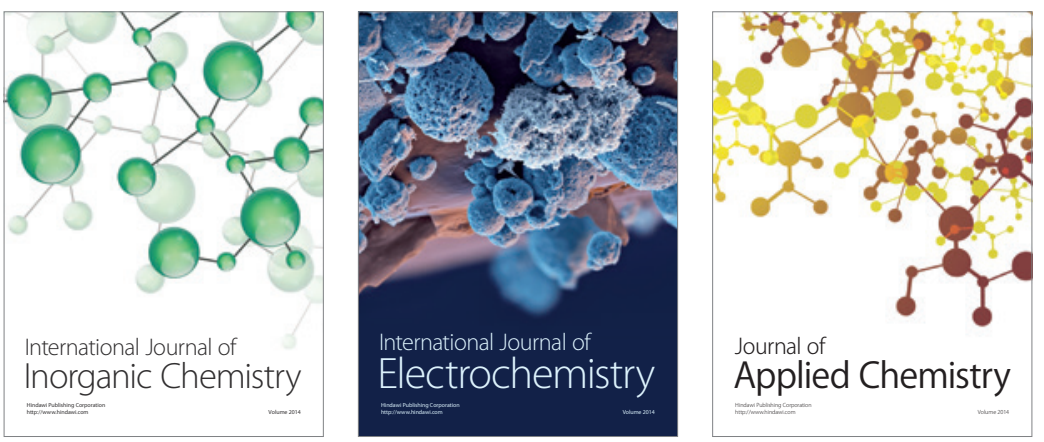

Journal of

Applied Chemistry
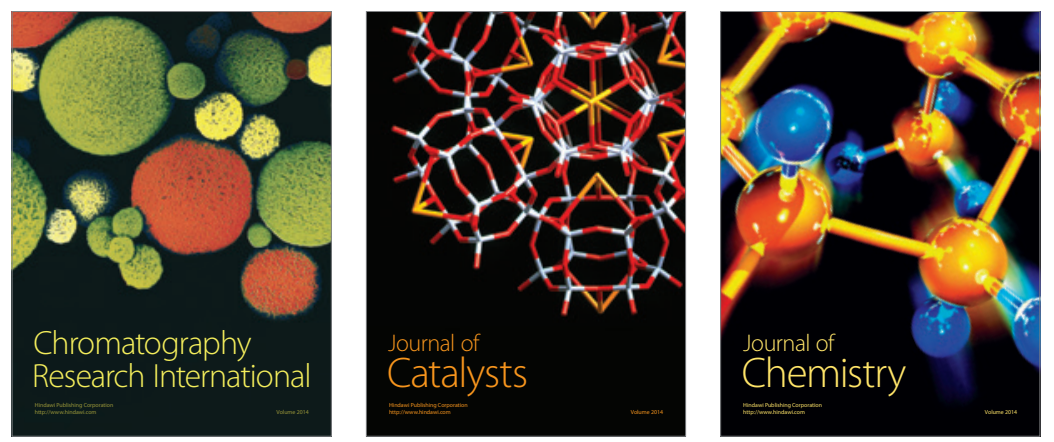
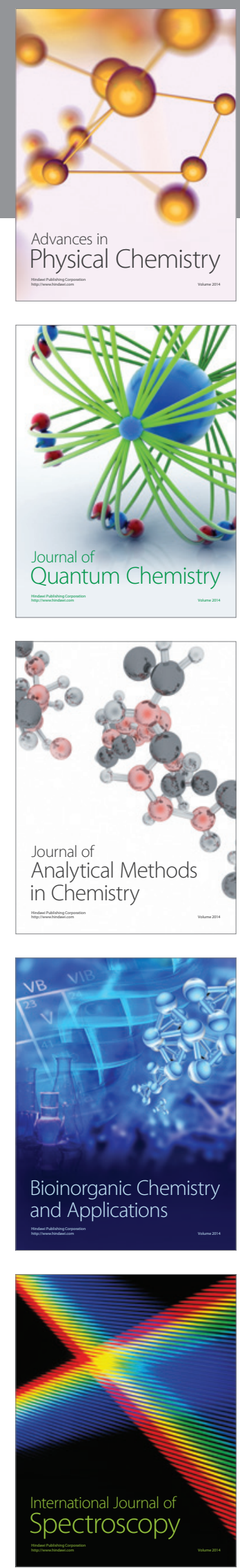